development of minimum unit pricing for alcohol as a public health policy in Scotland.

Results PET highlights the importance of redefining the policy problem so that it becomes a focus for policymaking. This therefore suggests reframing of alcohol as a public health problem amenable to a population-based solution has been instrumental in bringing about consideration of MUP. A multi-level governance framework suggests that the devolution of health (but not trade or taxation policy) to Scottish Parliament illustrates how public health advocates were able to 'venue shop' from Westminster to the Scottish Parliament. We also provide a necessary description of the process through which MUP has emerged.

Conclusion Political science theories are useful for understanding public health policy developments and could be more widely used by the public health community to inform advocacy or engagement with policymakers. This case study illustrates their value as well as providing more generalisable lessons for public health advocates (such as to seek opportunities for 'venue shopping' and an appreciation of the importance of framing of policy issues).

\section{PS51 COULD MORE THAN THREE MILLION OLDER PEOPLE BE AT RISK OF ALCOHOL-RELATED HARM? A CROSS. SECTIONAL ANALYSIS OF AGE-SPECIFIC DRINKING GUIDELINES}

doi:10.1136/jech-2012-201753.150

C Knott, S Scholes, NJ Shelton. Epidemiology and Public Health, UCL, London, UK

Background To determine the effect of recently proposed age-specific alcohol consumption guidelines upon the estimated proportion and number of older individuals potentially at risk of alcohol-related harm. Nationally representative cross-sectional population data from Health Survey for England (HSE).

Methods Random sample of the general population living in private households in England. For reliable comparison of adult alcohol consumption by age and sex across a five-year period, data were extracted from HSE 2003 and 2008 for all participants aged 16 or over. The sample included those who drank in the previous week, never drinkers, non-drinkers and adults who reported not having consumed alcohol in the week prior to interview. Excluded from the sample were those for whom data on drinking behaviour or unit alcohol consumption were missing (around one per cent of the total available sample). The sample from HSE 2003 thus comprised 14,718 participants, while the 2008 sample comprised data on 14,939 individuals.

Results The total number of individuals aged 65 or over classified as drinking in excess of daily recommended limits would have increased to over three million in 2008 under age-specific guidelines proposed by the Royal College of Psychiatrists, equating to an at-risk population of 809,000 individuals greater than found within the 16-24 age group during the same year. Proposed revisions to existing binge drinking classifications defined almost $1,200,000$ people aged 65 or over as hazardous consumers of alcohol in 2008 , equating to a rise of $258 \%$ by comparison with existing definitions.

Conclusion The introduction of new age-specific drinking guidelines put forward by the Royal College of Psychiatrists would increase the elderly population drinking in excess of daily recommended limits by more than two-fold, and increase by more than three-fold the number of binge drinkers. However, there remains at present a dearth of evidence sufficient for guiding age-specific revisions to existing and already problematic alcohol consumption thresholds. Nevertheless, vigilance regarding heavy late-life drinking remains important in light of older people's heightened sensitivity to the effects of alcohol and the rising number within the sub-population potentially at risk of alcoholrelated harm.

\section{PS52 ARE THERE GENDER DIFFERENCES IN THE SOCIAL PATTERNING OF BINGE DRINKING IN THE CZECH REPUBLIC, RUSSIA, POLAND AND LITHUANIA? A CROSS- SECTIONAL STUDY}

doi:10.1136/jech-2012-201753.151

L Asher, H Pikhart, M Bobak. Epidemiology and Public Health, UCL, London, UK

Background Binge drinking may have played a central role in mortality fluctuations in the former Soviet Union (fSU). In Eastern Europe, binge drinking is more common in men than women and in men of lower socio-economic position (SEP). Yet intersections of these factors have rarely been addressed with sufficient power to detect social patterns in binge drinking amongst women. The aim of this study was to determine whether there are gender differences in the social patterning of binge drinking in the Czech Republic, Russia, Poland and Lithuania.

Methods Cross-sectional baseline data from the HAPIEE (Health, Alcohol and Psychosocial factors in Eastern Europe) study was used. The participants were men and women aged $45-69$ years randomly selected from population registers in the Czech Republic, Russia, Poland and Lithuania. Logistic regression was used to examine the association between social factors (education, employment status, household amenities and deprivation) and binge drinking $(>100 \mathrm{~g}$ (men) and $>60 \mathrm{~g}$ (women) ethanol per occasion $\geq 1 \mathrm{x} /$ month) in each gender and country separately. Amenities score was derived from 18 (Lithuania) or 12 (other countries) individual questions on household items. 'Few amenities' was defined as a score in the lowest quartile for the participant's country.

Tests for interaction between gender and each variable were carried out. Tests for interaction between country and each variable were also completed. Pooled data (all countries) was interpreted where there was no evidence of country heterogeneity.

Results There were 34,069 participants with complete data. Amongst men in all countries, all markers of low SEP were associated with increased odds of binge drinking (e.g. OR $1.22,95 \% \mathrm{CI}$ 1.10-1.35 for few amenities, fully adjusted model). In women, few amenities (OR 0.81, 0.70-0.94, fully adjusted model), and to a lesser extent low education level, were associated with decreased odds of binge drinking. The associations between social factors, gender and binge drinking were homogenous between countries (few amenities test for country heterogeneity $\mathrm{p}=0.72 \mathrm{men}, \mathrm{p}=0.51$ women) with the exceptions of education and deprivation in women.

Conclusion In Russia and Eastern Europe binge drinking in men and women is socially patterned, but in contrasting ways. Men with lower SEP may binge drink due to social instability and poor coping mechanisms. Women with higher SEP may binge drink due to greater resources and exposure to, and adoption of, male drinking patterns through employment or higher education. Policy to tackle binge drinking should take into account its gender-specific social determinants.

\section{PS53 EFFECT OF GEOGRAPHICAL ACCESS TO HEALTH FACILITIES ON CHILD MORTALITY IN RURAL ETHIOPIA: A COMMUNITY BASED CROSS SECTIONAL STUDY}

doi:10.1136/jech-2012-201753.152

${ }^{1} Y$ Okwaraji, ${ }^{1} \mathrm{C}$ Cousens, ${ }^{2} Y$ Berhane, ${ }^{1} \mathrm{~K}$ Mulholland, ${ }^{1} \mathrm{~K}$ Edmond. ${ }^{1}$ Epidemiology \& Population Health, LSHTM, London, UK; ${ }^{2}$ Epidemiology \& Biostatistics, Addis Ababa University, Addis Ababa, Ethiopia

Background There have been few studies which have examined associations between access to health care and child health outcomes in remote populations most in need of health services. This study assessed the effect of travel time and distance to health facilities on mortality in children under five years in a remote area of rural north-western Ethiopia. 
Methods This study involved a randomly selected cross sectional survey of 2,058 households. Data were collected during home visits to all resident women of reproductive age (15-49 years). A geographic information system (GIS) was used to map all households and the only health centre in the district. The analysis was restricted to 2,206 rural children who were under the age of five years during the five years before the survey. Data were analysed using random effects Poisson regression.

Results $90.4 \%(1,996 / 2,206)$ of children lived more than 1.5 hours walk from the health centre. Children who lived $\geq 1$. 5 hrs from the health centre had a two-three fold greater risk of death than children who lived $<1.5$ hours from the health centre (children with travel time 1.5-<2.5hrs adjusted relative risk [adjRR] 2.3[0.95-5.6], travel time 2.5-<3.5hrs adjRR 3.1[1.3-7.4] and travel time 3.5$<6.5 \mathrm{hrs}$ adjRR 2.5[1.1-6.2]).

Conclusion Distance to a health centre had a marked influence on under five mortality in a poor, rural, remote area of Ethiopia. This study provides important information for policy makers on the likely impact of new health centres and their most effective location in remote areas.

\section{PS54 BIOMARKERS ASSOCIATED WITH MORTALITY IN A COMMUNITY BASED POPULATION WITH CARDIOVASCULAR RISK FACTORS: DATA FROM THE SCREENING TO PREVENT HEART FAILURE (STOP HF) STUDY}

doi:10.1136/jech-2012-201753.153

${ }^{1,2} \mathrm{CM}$ Conlon, ${ }^{1} \mathrm{CC}$ Kelleher, ${ }^{2} \mathrm{D}$ Dawkins, ${ }^{3} \mathrm{~L} \mathrm{McD}$ onald, ${ }^{2} \mathrm{M}$ Ledwidge, ${ }^{2,3 \mathrm{~K}} \mathrm{McD}$ Donald 'School of Public Health, Physiotherapy \& Population Science, University College Dublin, Dublin, Ireland; 'Heart Failure Unit, St Vincent's University Hospital, Dublin, Ireland, ${ }^{3}$ School of Medicine, University College Dublin, Dublin, Ireland

Background The STOP HF cohort is an ongoing longitudinal study of 1,040 individuals with cardiovascular risk factors and no known ventricular dysfunction at baseline. The study is located in South Dublin and the Southeast of Ireland. This is an analysis of the deaths reported at the interim analysis conducted in January 2012 (mean follow-up, 4 years, range 3.5-7.0 years).

Methods Univariable analyses compared the profiles of survivors to those deceased. Logistic regression identified the foremost associates of death. Cox's proportional hazard models estimated the risk of death over time, considering the presence of certain factors.

Results Between January 2005 and April 2008 1,040 individuals were recruited into the STOP HF study (Mean age 65, 49\% male, hyperlipidemia $53 \%$, hypertension $47 \%$, CAD 16\%, MI $8 \%$, arrhythmia $8 \%$, diabetes $12 \%$, smoker $14 \%$ ). At the interim analyses 64 deaths were reported, (6.1\% of the cohort). Univariable analyses indicated those deceased were older ( $65 \mathrm{vs.} 71$ years, $p<0.0001)$ with lower diastolic blood-pressure $(p<0.005)$ and a $17 \%$ greater prevalence of diabetes $(p<0.0001)$. Those deceased had biomarker levels more frequently $\geq 75$ th percentile for gender in BNP $(p<0.005)$, hsCRP $(p<0.0001)$, Urea $(p<0.005)$, Creatinine $(p<0.0001)$ and ALP $(p<0.05)$ and were more likely to be taking ACE inhibitor $(p<0.02)$ and anti-diabetic therapy $(p<0.0001)$. The final multivariable model identified age $(\operatorname{ExpB}=1.07, \mathrm{OR} 1.03-1.11, \mathrm{p}<0.0001)$, diabetes $(\operatorname{ExpB}=3.44, \mathrm{OR} 1.96-7.00, \mathrm{P}=0.001), \mathrm{BNP}(\operatorname{ExpB}=1.00$, OR 1.0001.007, $\mathrm{p}=0.075)$ and hsCRP $(\operatorname{ExpB}=1.07, \mathrm{OR} 1.04-1.11, \mathrm{p}<0.000)$ as associates of mortality (model $\chi 2(4, \mathrm{~N}=1041)=50.240, \mathrm{p}<0.001$ ). Controlling for age, cox's proportional hazard models indicated that those with diabetes had a 3 times higher risk of death $(\operatorname{ExpB}=3.117$, OR 1.801-5.304, $\mathrm{p}<0.0001$ ); those with a hsCRP level $\geq 75$ th percentile for gender were almost 3.5 times more likely to die $(\operatorname{ExpB}=3.439$, OR 1.995-5.498, $\mathrm{p}<0.0001$ ) and those with ALP $\geq 75$ th percentile for gender were also more likely to die durin the follow-up period (ExpB=1.919, OR 1.096-3.359).

Conclusion Diabetes is associated with in excess of a 3 times increase in the likelihood of death over 4 years follow-up in this population, while other morbid conditions such as coronary disease and atrial fibrillation show no significant association. Despite aggressive cardiovascular risk management through primary and secondary prevention strategies, those with diabetes continue to have a poor prognostic outlook. Observation of biomarkers such as hsCRP and ALP may be of added value in monitoring cohorts with existing cardiovascular risk factors and identifying those that may be subclinically manifesting heightened risk of mortality in this setting.

\section{PS55 THE USE OF A WEALTH INDEX WITHIN AN IMPOVERISHED COMMUNITY: A COHORT STUDY IN KWAZULU-NATAL, SOUTH AFRICA}

doi:10.1136/jech-2012-201753.154

1,2LL Davidson, ${ }^{3} \mathrm{~S}$ Kauchali, ${ }^{3} \mathrm{MK}$ Chhagan, ' $\mathrm{F}$ Bah, ${ }^{200 T}$ Uwemedimo, ${ }^{3} \mathrm{MH}$ Craib, ${ }^{4}$ McKeague. 'Epidemiology, Columbia University, New York City, USA;²Pediatrics, Columbia University, New York City, USA; ${ }^{3}$ Child Health, University of KwaZulu-Natal, Durban, South Africa; ${ }^{4}$ Biostatistics, Columbia University, New York, USA

Background An index of wealth is widely used in national surveys to create economic profiles. We constructed such an index within a population-based cohort study of 1,788 preschool children and their primary caregivers living in five isiZulu tribal areas of KwaZuluNatal, South Africa, an extremely poor area which remains at the epi-center of the South African HIV/AIDS epidemic.

Methods Study Design: Information on household assets, employment, household structure was obtained by door-to-door survey alongside a screen for child disability in developing countries. All children were invited to a structured medical and psychological assessment for disability and HIV status of child and primary caregiver. Wealth Index: A household asset index developed within our study population used many items identical to those in WHO DHS surveys, employing a principal components approach. Asset indicators were grouped into 3 categories: land ownership, ownership of consumer goods, and characteristics of household dwelling (building material, water sources, toilet facility, energy source, etc.). Factor analysis was performed: variables with zero variances and all variables with prevalence less than $2 \%$ were removed. The first component explained $16 \%$ of the variance and a $\mathrm{KMO}$ of 0.532 . We ranked the factor scores on the first component in ascending order, standardized to a range of 0 to 4 , and grouped into tertiles ( 1 =lowest third, $2=$ middle third, $3=$ top third).

Results The wealth index gave information about study participation: Of 1788 children screened, children from households in the poorest third were significantly more likely to be brought to the assessment: $91 \%$ compared to 83 and $89 \%$ in the middle and top third respectively. Significant differences in the wealth index were found between the five areas in the sample. With regard to caregiver responses about child disability, those in the poorest third were most likely to report that their child had a disability (43\% compared to 46 and $49 \%$ - significant on test for trend). Though doctors found a lower rate of disability than reported by parents, there was no difference in disability or false positives rate by wealth index tertile HIV seropositivity of caregiver varied by tertile $(30.3 \%, 28.5 \%$ and $21.8 \%$ in poorest, middle and least poor) but not that of children. Conclusion Even within extremely deprived areas in a low or middle income country, a wealth index can assess comparative risk among groups suffering more or less material disadvantage and also provide important information in assessing possibility of selection bias in the findings.

\section{PS56 RISK OF INTENTIONAL SELF-HARM IN YOUNG PEOPLE WITH SELECTED MENTAL AND CHRONIC PHYSICAL CONDITIONS IN ENGLAND}

doi:10.1136/jech-2012-201753.155

0 Seminog, M Goldacre. Department of Public Health, University of Oxford, Oxford, UK 